EMBRYARIDDLE
Aeronautical University

SCHOLARLY COMMONS

\section{International Journal of Aviation,} Aeronautics, and Aerospace

\title{
Comparative Study on the Prediction of Aerodynamic Characteristics of Mini - Unmanned Aerial Vehicle with Turbulence Models
}

\author{
Somashekar V \\ Vellore Institute of Technology, Vellore, shekar.mtech.ph.d@gmail.com \\ Immanuel Selwyn Raj A \\ Vellore Institute of Technology, Vellore, immanuel.selwynraj@vit.ac.in
}

Follow this and additional works at: https://commons.erau.edu/ijaaa

Part of the Aerodynamics and Fluid Mechanics Commons, and the Aeronautical Vehicles Commons

\section{Scholarly Commons Citation}

V, S., \& A, I. (2021). Comparative Study on the Prediction of Aerodynamic Characteristics of Mini Unmanned Aerial Vehicle with Turbulence Models. International Journal of Aviation, Aeronautics, and Aerospace, 8(1). https://doi.org/10.15394/ijaaa.2021.1559

This Article is brought to you for free and open access by the Journals at Scholarly Commons. It has been accepted for inclusion in International Journal of Aviation, Aeronautics, and Aerospace by an authorized administrator of Scholarly Commons. For more information, please contact commons@erau.edu. 
V and A: Comparative Study on the Prediction of Aerodynamic Characteristics of M ini - UAV with Turbulence M odels

Various definitions of Small Unmanned Aerial Vehicles (SUAVs) have been given by national regulatory authorities. These definitions sometimes do not include the size precisions and differ about the weight measurement specifications. Moreover, these definitions can have a range of less than $2 \mathrm{~kg}$ for Canada to less than $25 \mathrm{~kg}$ for the United States (Federal Aviation Administration [FAA], 2015). The prospective aspect of UE's Single European Sky ATM Research (SESAR) for the 2020 Air Traffic Management rules has also proposed less than $25 \mathrm{~kg}$ (SESAR-reviewed SUAS definition; SESARJU, 2021) while UK's Civil Aviation Authority (CAA) has stated less than $20 \mathrm{~kg}$ (CAA's SUAS definition; Civil Aviation Authority, 2015).

The appreciation for the long-endurance unmanned aerial vehicles (UAVs) in the coming years' airfields will be growing as they have the versatility to occupy into many applications, for instance carrying out strategic reconnaissance, offering telecommunication links, and assisting in metrological research, forest fire detection, disaster monitoring, border security, resource exploration, wildfire detection (Park et al., 2018; Son et al., 2016; Wang et al., 2013). Although high altitude UAVs flying are capable of operating continuously for a long time, low altitude UAVs are still wanted as they are more efficient to gather close-range information (Lin, 2008; Savla et al., 2008). Usually, low altitude UAVs have several abilities such as on-site information gathering, target classification, photogrammetric survey, or audio broadcasting and with these abilities, low altitude long endurance UAVs maybe become more effective for disaster prevention and relief.

At the beginning of the last century, the first contacts with turbulence modelling emerged which was before the invention of the first computer. One of the forerunners was Prandtl who published his mixing-length hypothesis in 1925 (FAA, 2015). It was far from the modern models, but as all the calculations were done by hands, the prime concentration was to alleviate the number of operations as many as possible.

Right after the Second World War, the first computers got familiar with the intention of scientific research. A new interest in turbulence modelling emerged in the same period due to the development of jet engines, supersonic aircraft, and some other technologies which required more accurate simulations. Several turbulence models were manifested during the period of 1940s-1960s. These were the first attempts of accurate prediction of near-wall layer turbulence flows.

But it was the beginning of the 1970s when the modern turbulence models were invented. The prime acquisition was the invention of the parent 3 equation model by Hanjalic and Launder (1972) and then the original 2 equation k- $\varepsilon$ model by Launder and Spalding (1974). There were some limitations found in the latter model such as inaccurate prediction of low Reynolds near-wall flows. The first 
modification of the k- $\varepsilon$ model for a specific type of flow (Son et al., 2016) arisen in 1972, way before the paper on the finalized original model (CAA's SUAS definition) was revealed. Other turbulence models for the accurate prediction of the boundary layer behaviour appeared at the same time (e.g., Ng \& Spalding model, 1972; Park et al., 2018) for turbulent kinetic energy k and turbulent length scale 1 , but k- $\varepsilon$ with its modification turned out to be one of the most widespread models in the CFD world.

Another iconic turbulence model was introduced by Wilcox in 1988, which was based on the same Boussinesq Hypothesis (or eddy viscosity assumption) and employed the same turbulent kinetic energy (Wang, 2013). But instead of dissipation rate $\varepsilon$, specific dissipation rate $\omega$ was used in this model. Later, Menter (1994) described a modified model named Menter SST k- $\varepsilon$ model (Savla et al., 2008), which was used along with the original model and lots of its other modifications. Another well-known turbulence model known as the SpalartAllmaras model was introduced by Spalart and Allmaras in 1992 (Lin et al., 2008). This model directly employed one equation for turbulent viscosity to close the Reynolds stress tensor in RANS. This model was generally developed for external aerodynamic flows and for this reason, it is suitable for modelling unmanned aerial vehicles.

So, it can be stated that at the beginning of the 1990s different types of models and their modifications were invented to simulate turbulent flows. But the selection of the models for a particular application is not an obvious decision and generally is subjected to a separate study. That was the principal cause for various research to include turbulence models comparison.

Different researchers have published many articles on the RANS turbulence models related to the aviation industry. For instance, Voloshin modified the airship model using various turbulence models i.e., k- $\varepsilon$, two k- $\omega$ and Spallart-Allmaras models based on eddy viscosity assumption. This analysis found that the Spalart-Allmaras turbulence model is the most optimal for accuracy and resource consumption to simulate the airships flying at small (near zero) and medium (about $10^{\circ}$ ) angles of attack. But, usually for large angles of attack the standard k- $\varepsilon$ model operates more accurately than the Spalart-Allmaras model. Alternatively, it sometimes uses more CPU time. That is the reason, SpalartAllmaras turbulence model is stated as the best choice for the simulation of airships flying at large (about $35^{\circ}$ ) angles of attack (Voloshin et al., 2012).

Moreover, Coombs et al. (2021), also investigated the performance of eight turbulence models by a wing-in-junction flow test using incompressible Reynolds-averaged Navier-Stokes (RANS) simulations and it was commented that the Realisable k- $\varepsilon$ model and second-moment closure models showed the closest agreement to the experimental data (Coombs et al., 2012). 
V and A: Comparative Study on the Prediction of Aerodynamic Characteristics of M ini - UAV with Turbulence M odels

Jang et al. (2018) did their experiment on the numerical analyses of threedimensional aircraft (i.e., four aircraft are considered - ARA-M100, DLR-F6 wing-body, DLR-F6 wing-body-nacelle-pylon, and a high wing aircraft with nacelles) and compared the outputs of several turbulence models such as SparlartAllmaras (SA) model, Coakley's q- $\omega$ model, Huang and Coakley's k- $\varepsilon$ model, and Menter's k- $\omega$ SST model to determine the aerodynamic characteristics of the aircraft. The k- $\omega$ SST model was found to be able to portend the smallest skin friction drag, while the k- $\varepsilon$ model portended the largest skin friction drag for all configurations. All the turbulence models forecast corresponding pressure drag except near stall. Here, the k- $\varepsilon$ model usually forecasts the stall earlier than the other models. The trifles of the flow structure near the wing surface can be exceptionally different from model to model, especially the separation patterns (Jang et al., 2018).

Kwak et al. (2012) examined the numerical simulations of aircraft configurations using different types of turbulence models, for example - the q- $\omega$ turbulence model, the k- $\omega$ SST turbulence model, and several versions of the SST model, to estimate an aircraft's aerodynamic characteristics. They denoted that the wing-body (WB) configuration of the k- $\omega$ SST model underestimated skin friction drag while the q- $\omega$ model overestimated skin friction drags. The impacts upon the aerodynamic performance and characteristics initiated by change-over of the k- $\omega$ SST model asserted to be insignificant. Yet, in the wing-body-nacelle-pylon (WBNP) configuration simulations, the total drag coefficients calculated by the k$\omega$ SST model correlated nicely with the experimental data for negative incidences (Kwak et al., 2012).

Maani et al., (2018) concluded that different types of turbulence models such as Spalart-Allmaras (S-A), standard k- $\varepsilon$, k- $\varepsilon$ RNG, standard k- $\omega$ and k- $\omega$ SST, are capable of facilitating the calculation of characteristic quantities to optimize the simulation of turbulent flows in aerodynamics. It was also stated that the five turbulence models have identical usual behaviour with a few differences in the pressure values on the upper surface and aerodynamic lift and drag coefficients. They pointed out that Spalart-Allmaras, k- $\varepsilon$ RNG and k- $\omega$ SST models are the most effective models to describe the turbulence of the transonic flow around an ONERA M6 wing (Maani et al., 2018).

This report investigated the abilities of the turbulence models especially Spalart-Allmaras, k- $\varepsilon$ standard, k- $\varepsilon$ RNG, k- $\varepsilon$ Realizable, k- $\omega$ standard, and k- $\omega$ SST model, on the long endurance Mini-UAV at subsonic speed $(\mathrm{M}=0.04)$. The aim is to trace the superior turbulent model for subsonic flow using the RANS turbulence model. This new report quantifies the aerodynamic characteristics of a Mini-UAV (Bronz et al., 2013) using RANS models in Fluent. In this manner, it becomes essential and significant to exercise the RANS turbulence model on Mini-UAV aerodynamics. Here, the Mini-UAV's outputs are used for the 
comparison and evaluation of the six turbulence models such as Spalart-Allmaras, k- $\varepsilon$ standard, k- $\varepsilon$ RNG, k- $\varepsilon$ Realizable, k- $\omega$ standard, and k- $\omega$ SST model, so that the aerodynamic characteristics can be determined at subsonic flow condition and it can also establish a verified solution method. Then, the numerical data obtained are compared with experimental data in this study (Bronz et al., 2013).

\section{Numerical Approach}

The numerical simulations of the flow around the long endurance MiniUAV were carried out using the commercial CFD software, ANSYS 15. Using ICEM-CFD, the O-type grid was generated with pressure-far-field boundary conditions, as shown in Figure 1. The total number of elements is the combination of QUADS (54992) and HEXAS (613353) which is equal to 668345. The total number of nodes found is 641075. Figure $1 \& 2$ shows the grid generation and boundary conditions over the Mini-UAV. The numerical simulation was performed for different flight conditions, i.e. $-4^{\circ}$ to $40^{\circ}$ at Mach number 0.04, and different turbulence flow models are considered i.e., Spalart-Allmaras, k- $\varepsilon$ standard, k- $\varepsilon$ RNG, k- $\varepsilon$ Realizable, k- $\omega$ standard, and k- $\omega$ SST model. We used the existing Mini-UAV design for our simulation (Bronz et al., 2013). The farfield incoming air has a velocity of $14 \mathrm{~m} / \mathrm{s}$ (Bronz et al., 2013). 


\section{Figure 1}

Computational grid around the Mini-UAV

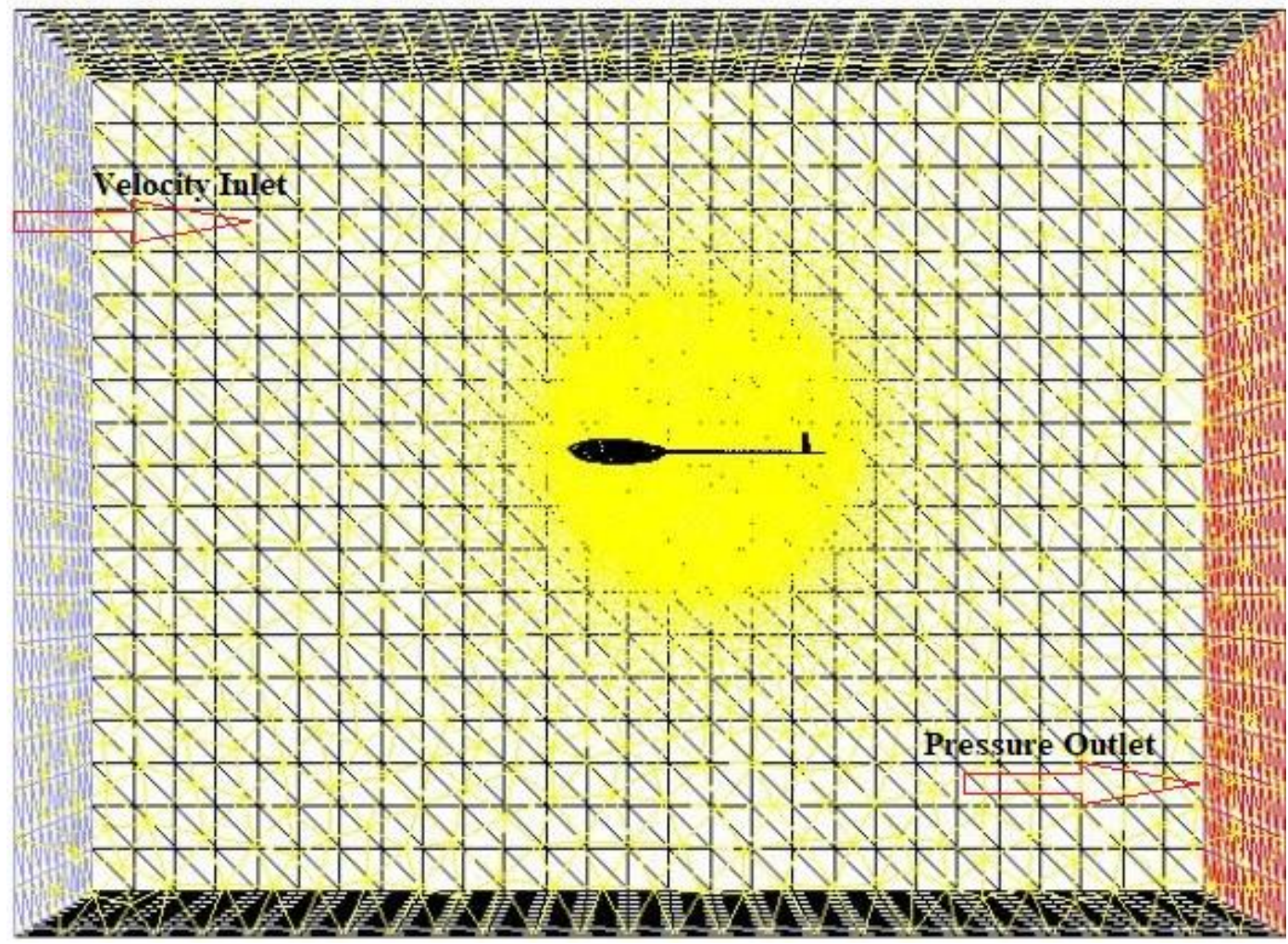

Figure 2

Computational Mesh on Mini-UAV Surface and Symmetry Plane

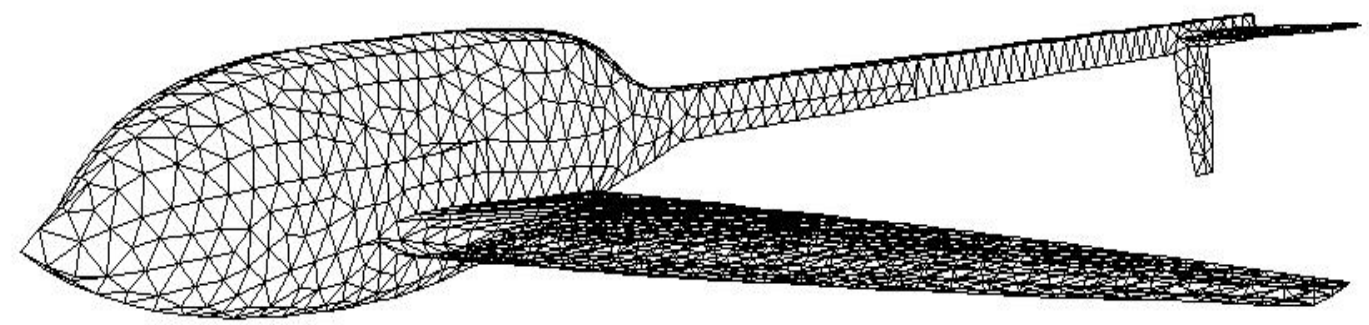

In this study, the aerodynamic efficiency of the airfoil is calculated by the coefficients of lift and drag, which are defined as follows: 


$$
\begin{aligned}
C_{L} & =\frac{L}{1 / 2 \rho_{\infty} v_{\infty}^{2} S_{\text {ref }}} \\
C_{D} & =\frac{D}{1 / 2 \rho_{\infty} v_{\infty}^{2} S_{\text {ref }}}
\end{aligned}
$$

Where, $C_{D}$ is the drag coefficient and $C_{L}$ is the lift coefficient, D is the drag, $\mathrm{L}$ is the lift, $v_{\infty}$ is the air free-stream velocity, $S_{r e f}$ is the reference area or the wing area of an aircraft measured in square meters, and $\rho_{\infty}$ is the density of air.

\section{Mathematical Formulation and Turbulence Models}

Usually, the turbulence models try to improve the original unsteady Navier-Stokes equations by proposing averaged and fluctuating quantities to fabricate Reynolds-averaged Navier-Stokes equations (RANS). These equations illustrate only the major quantities of the flux while modelling the impacts of turbulence without the requirement to solve turbulent fluctuations. All stages of the turbulence area are modelled. The turbulence models based on the RANS equations are acquainted as statistical turbulence models since the statistical mean method is used to gain the equations. The starting point of any numerical flow simulation is the set of Navier-Stokes equations in their instantaneous structure plus the fluid state equation for closing the process.

Two alternative procedures can be appointed to render the Navier-Stokes equations tractable so that the small-scale turbulent fluctuations do not have to be simulated immediately: Reynolds-averaging (or ensemble-averaging) and filtering. Both of the procedures bring in additional terms in the governing equations that are modelled sometimes to acquire a "closure" for the unknowns (Maani et al., 2018).

The Reynolds mean Navier-Stokes (RANS) equations for an unsteady flow of a compressible fluid can be demonstrated based on the spatial domain, such as:

$$
\begin{aligned}
& \frac{\partial \rho}{\partial t}+\frac{\partial}{\partial x_{i}}\left(\rho u_{i}\right)=0 \\
& \begin{aligned}
\frac{\partial}{\partial t}\left(\rho u_{i}\right)+\frac{\partial}{\partial x_{i}} & \left(\rho u_{i} u_{j}\right) \\
& =-\frac{\partial p}{\partial x_{i}}+\frac{\partial}{\partial x_{j}}\left[\mu\left(\frac{\partial u_{i}}{\partial x_{j}}+\frac{\partial u_{j}}{\partial x_{i}}-\frac{2}{2} \delta_{i j} \frac{\partial u_{l}}{\partial x_{l}}\right)\right] \\
& +\frac{\partial}{\partial x_{j}}\left(-\rho \overline{u_{l}^{\prime} u_{j}^{\prime}}\right)
\end{aligned}
\end{aligned}
$$

\section{Spalart-Allmaras (S-A) model}

The Spalart-Allmaras model is comparatively an easy one-equation model that resolves a modelled transport equation for the kinematic eddy (turbulent) viscosity (Maani et al., 2018, Spalart \& Allmaras, 2012). This synthesizes a relatively new category of the one-equation model in which it is not obligate to determine a 
length scale related to the local shear layer thickness. The Spalart-Allmaras model was planned specifically for the aerospace applications involving wall-bounded flows and has exhibited satisfactory outputs for boundary layers subjected to ambivalent pressure gradients. It is also receiving popularity for turbomachinery applications.

The transported variable in the Spalart-Allmaras model $\tilde{v}$ is similar to the turbulent kinematic viscosity except in the near-wall (viscous-affected) region. The transport equation for $\tilde{v}$ can be written as:

$$
\begin{aligned}
\frac{\partial}{\partial t}(\rho \tilde{v})+\frac{\partial}{\partial x_{i}} & \left(\rho \tilde{v} u_{i}\right) \\
& =G_{v}+\frac{1}{\sigma_{\tilde{v}}}\left[\frac{\partial}{\partial x_{i}}\left\{(\mu+\rho \tilde{v}) \frac{\partial \tilde{v}}{\partial x_{i}}\right\}+C_{b 2} \rho\left(\frac{\partial \tilde{v}}{\partial x_{i}}\right)^{2}\right]-Y_{v} \\
& +S_{\tilde{v}}
\end{aligned}
$$

Where, $\boldsymbol{G}_{\boldsymbol{v}}$ is the production of turbulent viscosity, $\boldsymbol{Y}_{\boldsymbol{v}}$ is the destruction of turbulent viscosity that happens in the near-wall region because of the wall blocking and viscous damping, $\boldsymbol{\sigma}_{\widetilde{v}}$ and $\boldsymbol{C}_{\boldsymbol{b} \mathbf{2}}$ are constants, $\boldsymbol{v}$ is the molecular kinematic viscosity and $\boldsymbol{S}_{\widetilde{v}}$ is a user-defined source term. Here, it is to be noted that the turbulence kinetic $\boldsymbol{k}$ energy is not calculated in the Spalart-Allmaras model.

The production term $G_{v}$ can be modelled as:

$G_{v}=C_{b 1} \rho \tilde{S} \tilde{v}$

$$
\text { where: } \tilde{S} \equiv S+\frac{\tilde{v}}{k^{2} d^{2}} f_{v 2} \text { and } f_{v 2}=1-\frac{x}{1+x f_{v 1}}
$$

$C_{b 1}$ and $k$ are constants, $d$ is the distance from the wall and $S$ is a scalar measure of the deformation tensor.

The destruction term is modelled as:

$$
\begin{aligned}
& Y_{v}=C_{\omega 1} \rho f_{\omega}\left(\frac{\tilde{v}}{d}\right)^{2} \\
& \text { Where: } f_{\omega}=\mathrm{g}\left[\frac{1+C_{\omega 3}^{6}}{\mathrm{~g}^{6}+C_{\omega 3}^{6}}\right]^{1 / 6}, \mathrm{~g}=\mathrm{r}+C_{\omega 2}\left(r^{6}-r\right) \text { and } r \equiv \frac{\tilde{v}}{\tilde{S} k^{2} d^{2}} \\
& C_{\omega 1}, C_{\omega 2} \text { and } C_{\omega 3} \text { are constants. }
\end{aligned}
$$

The model constants have the following values:

$$
\begin{gathered}
C_{b 1}=0.1355, C_{b 2}=0.622, \sigma_{\tilde{v}}=\frac{2}{3}, C_{v 1}=7.1, C_{\omega 1}=3.239, C_{\omega 2}=0.3, C_{\omega 3} \\
=2.0, k=0.4187
\end{gathered}
$$

\section{$\boldsymbol{k}-\boldsymbol{\varepsilon}$ Standard Model}

The simplest "complete models" of turbulence are two-equation models in which the solution of two individual transport equations offers the turbulent velocity and length scales to be independently calculated. Two-equation 
turbulence models approve the determination of both, a turbulent length and time scale by solving two separate transport equations. Apart from that, the standard $k$ $\varepsilon$ model (Launder \& Spalding, 1974; Maani et al., 2018) is based on model transport equations for the turbulence kinetic energy $(k)$ and its dissipation rate $(\boldsymbol{\varepsilon})$. Here, the model transport equation for $k$ is gained from the exact equation, while the model transport equation for $\boldsymbol{\varepsilon}$ is acquired from physical reasoning and it exhibits a little resemblance to its mathematically exact counterpart.

In the derivation of the $k-\boldsymbol{\varepsilon}$ model, the assumptions are - the flow is fully turbulent, and the effects of molecular viscosity are negligible. The standard $k-\boldsymbol{\varepsilon}$ model is, therefore, suitable only for fully turbulent flows.

The turbulence kinetic energy $k$ and its rate of dissipation $\boldsymbol{\varepsilon}$ are achieved by the following transport equations:

$$
\begin{array}{cc}
\frac{\partial}{\partial t}(\rho k)+\frac{\partial}{\partial x_{i}}\left(\rho k u_{i}\right)=\frac{\partial}{\partial x_{j}}\left[\left(\mu+\frac{\mu_{t}}{\sigma_{k}}\right) \frac{\partial k}{\partial x_{j}}\right]+G_{k}+G_{b}-\rho \varepsilon-Y_{M}+S_{k} & \text { Eq.8 } \\
\frac{\partial}{\partial t}(\rho \varepsilon)+\frac{\partial}{\partial x_{i}}\left(\rho \varepsilon u_{i}\right) & \\
= & \frac{\partial}{\partial x_{j}}\left[\left(\mu+\frac{\mu_{t}}{\sigma_{\varepsilon}}\right) \frac{\partial \varepsilon}{\partial x_{j}}\right]+C_{1 \varepsilon} \frac{\varepsilon}{k}\left(G_{k}+C_{3 \varepsilon} G_{b}\right)-C_{2 \varepsilon} \rho \frac{\varepsilon^{2}}{k} \\
& +S_{\varepsilon}
\end{array}
$$

$G_{k}$ is the generation of turbulence kinetic energy because of the mean velocity gradients, $G_{b}$ means the generation of turbulence kinetic energy because of buoyancy, $Y_{M}$ is the contribution of the fluctuating dilatation on compressible turbulence to the overall dissipation rate, $G_{1 \varepsilon}, G_{2 \varepsilon}$ and $C_{3 \varepsilon}$ are constants, $\sigma_{k}$ and $\sigma_{\varepsilon}$ are the turbulent Prandtl numbers for $k$ and $\varepsilon$, respectively, $S_{k}$ and $S_{\varepsilon}$ are the terms for source.

The turbulent (or eddy) viscosity $\mu_{t}$ is calculated by combining $k$ and $\boldsymbol{\varepsilon}$ as follows:

$\mu_{t}=\rho C_{\mu} \frac{k^{2}}{\varepsilon}$

Where, $C_{\mu}$ is a constant.

Here, the model constants have the following values-

$$
G_{1 \varepsilon}=1.44, C_{2 \varepsilon}=1.92, C_{\mu}=0.09, \sigma_{k}=1.00 \text { and } \sigma_{\varepsilon}=1.30
$$

\section{k- $\varepsilon$ RNG Model}

The $k-\boldsymbol{\varepsilon}$ RNG turbulence model is generated from the instantaneous Navier-Stokes equations, using a mathematical procedure called renormalization group RNG methods.

The $k-\varepsilon$ RNG model has an identical form to the standard model: 


$$
\begin{aligned}
\frac{\partial}{\partial t}(\rho k)+\frac{\partial}{\partial x_{i}} & \left(\rho k u_{i}\right) \\
= & \frac{\partial}{\partial x_{j}}\left(\alpha_{k} \mu_{e f f} \frac{\partial k}{\partial x_{j}}\right)+G_{k}+G_{b}-\rho \varepsilon-Y_{M}+S_{k} \\
\frac{\partial}{\partial t}(\rho \varepsilon)+\frac{\partial}{\partial x_{i}} & \left(\rho \varepsilon u_{i}\right) \\
& =\frac{\partial}{\partial x_{j}}\left(\alpha_{\varepsilon} \mu_{e f f} \frac{\partial \varepsilon}{\partial x_{j}}\right)+C_{1 \varepsilon} \frac{\varepsilon}{k}\left(G_{k}+C_{3 \varepsilon} G_{b}\right)-C_{2 \varepsilon} \rho \frac{\varepsilon^{2}}{k}-R_{\varepsilon} \\
& +S_{\varepsilon}
\end{aligned}
$$

$G_{k}$ is the generation of turbulence kinetic energy because of the mean velocity gradients, $G_{b}$ means the generation of turbulence kinetic energy because of buoyancy, $Y_{M}$ is the contribution of the fluctuating dilatation on compressible turbulence to the overall dissipation rate, $\sigma_{k}$ and $\sigma_{\varepsilon}$ are the inverse effective Prandtl numbers for $k$ and $\varepsilon$, respectively, $S_{k}$ and $S_{\varepsilon}$ are the terms of a source (Maani et al., 2018).

The scale elimination method in RNG theory produces a differential equation for turbulent viscosity:

$$
\begin{aligned}
& d\left(\frac{\rho^{2} k}{\sqrt{\varepsilon \mu}}\right)=1.72 \frac{\hat{v}}{\sqrt{\hat{v}^{3}-1+C_{v}}} d \hat{v} \\
& \text { where, } \hat{v}=\frac{\mu_{\text {eff }}}{\mu} \text { and } C_{v} \approx 100
\end{aligned}
$$

The only significant difference between the RNG and $k-\varepsilon$ standard models lies in the additional term in the $\varepsilon$ equation given by:

$$
\begin{aligned}
R_{\varepsilon}= & \frac{C_{\mu} \rho \eta^{3}\left(1-\frac{\eta}{\eta_{0}}\right)}{1+\beta \eta^{3}} \frac{\varepsilon^{2}}{k} \\
& \text { Where: } \eta \equiv \frac{S k}{\omega}, \eta_{0}=4.38, \beta=0.012, C_{1 \varepsilon}=1.42 \text { and } C_{2 \varepsilon}=1.68
\end{aligned}
$$

The production of turbulence kinetic energy $G_{k}$ is modeled identically for the standard $k$ - $\varepsilon$ model:

$G_{k}=-\rho \overline{u_{\imath}^{\prime} u_{\jmath}^{\prime}} \frac{\partial u_{j}}{\partial x_{i}}$

To assess $G_{k}$ in a manner consistent with the Boussinesq hypothesis:

$G_{k}=\mu_{t} S^{2}$

Where, $S$ is the modulus of the mean rate of the strain tensor, described as:

$S=\sqrt{2 S_{i j} S_{i j}}$

When using the high Reynolds number $k-\boldsymbol{\varepsilon}$ versions, $\mu_{\text {eff }}$ is employed instead of $\mu_{t}$. 


\section{The Realizable $k-\varepsilon$ Turbulence Model}

The simplest "complete models" of turbulence are two-equation models in which the solution of two independent transport equations allows the turbulent velocity and length scales to be independently computed. The standard $k-\boldsymbol{\varepsilon}$ model falls within this category of turbulence model and has become the workhorse of practical engineering flow calculations in the time since it was described by Launder and Spalding (1974). Robustness, economy, and reasonable accuracy for a wide range of turbulent flows interpret its popularity in industrial flow and heat transfer simulations.

It is a semi-empirical model and the derivation of the model equations is based on phenomenological considerations and empiricism. As the strengths and weaknesses of the standard $k-\boldsymbol{\varepsilon}$ model have become known, modifications have been done to the model to enhance its performance. Two of these variants are available: the RNG $k-\boldsymbol{\varepsilon}$ model and the Realizable $k-\boldsymbol{\varepsilon}$ model (Eleni et al., 2012; Shih et al., 1995). The modelled transport equations for $\mathrm{k}$ and $\varepsilon$ in the realizable $k$ $\varepsilon$ model are:

$$
\begin{aligned}
& \frac{\partial}{\partial t}(\rho k)+\frac{\partial}{\partial x_{j}}\left(\rho k u_{j}\right) \\
& =\frac{\partial}{\partial x_{j}}\left(\left(\mu+\frac{\mu_{t}}{\sigma_{k}}\right) \frac{\partial k}{\partial x_{j}}\right)+G_{k}+G_{b}-\rho \varepsilon-Y_{M}+S_{k} \\
& \begin{aligned}
& \frac{\partial}{\partial t}(\rho \varepsilon)+\frac{\partial}{\partial x_{j}}\left(\rho \varepsilon u_{j}\right) \\
&= \frac{\partial}{\partial x_{j}}\left[\left(\mu+\frac{\mu_{t}}{\sigma_{\varepsilon}}\right) \frac{\partial \varepsilon}{\partial x_{j}}\right]+\rho C_{1} S \varepsilon-\rho C_{2} \frac{\varepsilon^{2}}{k+\sqrt{v \varepsilon}}+C_{1 \varepsilon} \frac{\varepsilon}{k} C_{3 \varepsilon} G_{b} \\
&+S_{\varepsilon} \\
& \text { Where }, C_{1}=\max \left[0.43, \frac{n}{n+5}\right], n=S \frac{k}{\varepsilon}, S=\sqrt{2 S_{i j} S_{i j}}
\end{aligned}
\end{aligned}
$$

In these equations, $G_{k}$ is the generation of turbulence kinetic energy because of the mean velocity gradients. $G_{b}$ means the generation of turbulence kinetic energy because of buoyancy. $Y_{M}$ is the contribution of the fluctuating dilatation on compressible turbulence to the overall dissipation rate $\left(Y_{M}=2 \rho \varepsilon M_{t}^{2}\right.$, where $M_{t}$ is the turbulent Mach number). $C_{2}$ and $C_{1 \varepsilon}$ are constants. $\sigma_{k}$ and $\sigma_{\varepsilon}$ are the turbulent Prandtl numbers for $k$ and $\varepsilon$, respectively. $S_{k}$ and $S_{\varepsilon}$ are user-defined source terms.

The constants of the Realizable $k$ - $\varepsilon$ model are:

\section{$\boldsymbol{k}$ - $\omega$ Standard Model}

$$
G_{1 \varepsilon}=1.44, C_{2}=1.9, \sigma_{k}=1.0 \text { and } \sigma_{\varepsilon}=1.2
$$

The standard $k$ - $\boldsymbol{\omega}$ model relies on the Wilcox $k$ - $\boldsymbol{\omega}$ model (Maani et al., 2018; Wilcox, 1994) which incorporates improvements for low-Reynolds number 
effects, compressibility, and shear flow spreading. One of the impotent signs of the Wilcox model is the sensitivity of the solutions to values for $\boldsymbol{k}$ and $\boldsymbol{\omega}$ outside the shear layer (freestream sensitivity). The standard $k-\boldsymbol{\omega}$ model is an empirical model that depends on the model transport equations for the turbulence kinetic energy $(k)$ and the specific dissipation rate $(\boldsymbol{\omega})$, which can also be denoted as the ratio of $k$ to $\omega$.

As the $k$ - $\boldsymbol{\omega}$ model has been improved over the years, production terms have been added to both the $k$ and $\boldsymbol{\omega}$ equations, which have enhanced the accuracy of the model for predicting free shear flows. The turbulence kinetic energy, $k$, and the specific dissipation rate, are derived from the following transport equations:

$\frac{\partial}{\partial t}(\rho k)+\frac{\partial}{\partial x_{i}}\left(\rho k u_{i}\right)=\frac{\partial}{\partial x_{j}}\left(\Gamma_{k} \frac{\partial k}{\partial x_{j}}\right)+G_{k}-Y_{k}+S_{k}$
$\frac{\partial}{\partial t}(\rho \omega)+\frac{\partial}{\partial x_{i}}\left(\rho \omega u_{i}\right)=\frac{\partial}{\partial x_{j}}\left(\Gamma_{\omega} \frac{\partial \omega}{\partial x_{j}}\right)+G_{\omega}-Y_{\omega}+S_{\omega}$

$G_{k}$ is the generation of turbulence kinetic energy because of the mean velocity gradients, $G_{k}$ is the generation of $\boldsymbol{\omega}, \Gamma_{k}$ and $\Gamma_{\omega}$ denotes the effective diffusivity of $k$ and $\boldsymbol{\omega}$, respectively, $Y_{k}$ and $Y_{\omega}$ is the dissipation of $k$ and $\boldsymbol{\omega}$ because of the turbulence, $S_{k}$ and $S_{\omega}$ are the user-defined source terms.

The effective diffusivities for the $k-\boldsymbol{\omega}$ model are described as:

$\Gamma_{k}=\mu+\frac{\mu_{t}}{\sigma_{k}}$ and $\Gamma_{\omega}=\mu+\frac{\mu_{t}}{\sigma_{\omega}}$

Where, $\sigma_{k}$ and $\sigma_{\omega}$ are the turbulent Prandtl numbers for $\mathrm{k}$ and $\omega$, respectively. The result of turbulent viscosity $\mu_{t}$ is produced by combining $\mathrm{k}$ and $\omega$ as follows:

$\mu_{t}=\alpha^{*} \frac{\rho k}{\omega}$

The production of turbulence kinetic energy $G_{k}$ maybe given by:

$G_{k}=-\rho \overline{u_{\imath}^{\prime} u_{\jmath}^{\prime}} \frac{\partial u_{j}}{\partial x_{i}}$

To evaluate $G_{k}$ in a manner consistent with the Boussinesq hypothesis: $G_{k}=$ $\mu_{t} S^{2}$.

The production of $\omega$ is given by:

$G_{\omega}=\alpha \frac{\omega}{k} G_{k}$

The dissipation of $k$ is giving by:

$Y_{k}=\rho \beta^{*} f_{\beta^{*}} k \omega$

The dissipation of $\omega$ is giving by:

$Y_{\omega}=\rho \beta^{*} f_{\beta} \omega^{2}$

$Y_{k}$ and $Y_{\omega}$ are the dissipations of $k$ and $\omega$, and defined identically as in the standard $k$ - $\omega$ model. Model constants are: 


$$
\begin{gathered}
\sigma_{k, 1}=1.176, \sigma_{\omega, 1}=2.0, \sigma_{k, 2}=1.0, \sigma_{\omega, 2}=1.168, a_{1}=0.31, \beta_{i, 1}=0.075, \beta_{i, 2} \\
=0.0828, k=0.41
\end{gathered}
$$

\section{$k$ - $\omega$ SST Model}

The shear-stress transport (SST) $k$ - $\boldsymbol{\omega}$ model was demonstrated by Menter (Maani et al., 2018, Menter, 1994) and this model is capable of blending the robust efficiently and formulating the $k$ - $\boldsymbol{\omega}$ model accurately in the near-wall region with the freestream independence of the $k-\boldsymbol{\omega}$ model in the far-field.

The $k$ - $\boldsymbol{\omega}$ SST model has an identical structure to the standard $k$ - $\boldsymbol{\omega}$ model:

$$
\begin{aligned}
& \frac{\partial}{\partial t}(\rho k)+\frac{\partial}{\partial x_{i}}\left(\rho k u_{i}\right)=\frac{\partial}{\partial x_{j}}\left(\Gamma_{k} \frac{\partial k}{\partial x_{j}}\right)+G_{k}-Y_{k}+S_{k} \\
& \frac{\partial}{\partial t}(\rho \omega)+\frac{\partial}{\partial x_{i}}\left(\rho \omega u_{i}\right)=\frac{\partial}{\partial x_{j}}\left(\Gamma_{\omega} \frac{\partial \omega}{\partial x_{j}}\right)+G_{\omega}-Y_{\omega}+D_{\omega}+S_{\omega}
\end{aligned}
$$

Where, $D_{\omega}$ is the cross-diffusion term.

The turbulent viscosity $\mu_{t}$ is calculated as follows:

$$
\begin{aligned}
\mu_{t}=\frac{\rho k}{\omega} \frac{1}{\max \left[\frac{1}{\alpha^{*}}, \frac{S F_{2}}{a_{1} \omega}\right]} \\
\text { Where: } \sigma_{k}=\frac{1}{\frac{F_{1}}{\sigma_{k, 1}}+\frac{\left(1-F_{1}\right)}{\sigma_{k, 2}}} \text { and } \sigma_{\omega}=\frac{1}{\frac{F_{1}}{\sigma_{\omega, 1}}+\frac{\left(1-F_{1}\right)}{\sigma_{\omega, 2}}}
\end{aligned}
$$

Here, $F_{1}$ and $F_{2}$ are the blending functions.

$G_{k}$ means the formation of the turbulence kinetic energy, and is denoted as:

$G_{k}=\min \left(G_{k}, 10 \rho \beta^{*} k \omega\right)$

And, $G_{\omega}$ is the formation of $\omega$ and is given by:

$G_{\omega}=\frac{\alpha}{v_{t}} G_{k}$

The $k$ - $\boldsymbol{\omega}$ SST model depends on both the standard $k-\boldsymbol{\omega}$ model and the standard $k-\boldsymbol{\varepsilon}$ model. To combine these two models well, the standard $k-\boldsymbol{\varepsilon}$ model has been transformed into equations which are relied on the $k$ and $\omega$, and it leads to the indication of a cross-diffusion term $D_{\omega}$ that is stated as:

$D_{\omega}=2\left(1-F_{1}\right) \rho \sigma_{\omega, 2} \frac{1}{\omega} \frac{\partial k}{\partial x_{j}} \frac{\partial \omega}{\partial x_{j}}$

Model constants are:

$$
\begin{gathered}
\sigma_{k, 1}=1.176, \sigma_{\omega, 1}=2.0, \sigma_{k, 2}=1.0, \sigma_{\omega, 2}=1.168, a_{1}=0.31, \beta_{i, 1}=0.075, \beta_{i, 2} \\
=0.0828, k=0.41
\end{gathered}
$$

Here, the $k$ - $\boldsymbol{\omega}$ SST model has similar values as for the standard $k$ - $\boldsymbol{\omega}$ model.

\section{Results and Discussions}

Simulations for various angles of attack were done to compare the results from the different turbulence models (i.e., Spalart-Allmaras, k- $\varepsilon$ standard, k- $\varepsilon$ RNG, k- $\varepsilon$ Realizable, k- $\omega$ standard, and k- $\omega$ SST) and then to validate them with 
the existing experimental data from reliable sources. To do so, the model was solved with a range of different angles of attack from $-4^{\circ}$ to $40^{\circ}$ at Mach number 0.04 .

Figure 3 shows the lift coefficient vs. the angle of attack for six turbulence models (i.e., Spalart-Allmaras, k- $\varepsilon$ standard, k- $\varepsilon$ RNG, k- $\varepsilon$ Realizable, k- $\omega$ standard, and k- $\omega$ SST). The maximum coefficient of lift is found in the case of k$\varepsilon$ turbulence model at a stall angle of attack $\left(38^{\circ}\right)$, which is higher than that of the Spalart-Allmaras, k- $\omega$ standard, and k- $\omega$ SST models. The corresponding values reported for different turbulence models (i.e., Spalart-Allmaras, k- $\varepsilon$ standard, k- $\varepsilon$ RNG, k- $\varepsilon$ Realizable, k- $\omega$ standard, and k- $\omega$ SST) are 0.5, 0.53, 0.53, 0.53, 0.49, and 0.48 respectively at a stall angle of attack $\left(38^{\circ}\right)$. The maximum variation of the coefficient of lift among the six turbulence models is $9.43 \%$ at a stall angle of attack $\left(38^{\circ}\right)$. From the numerical results, it is seen that the coefficient of lift increased linearly with the angle of attack from $-4^{\circ}$ to $40^{\circ}$ without any variation (zero percent variation) for the $\mathrm{k}-\varepsilon$ standard, $\mathrm{k}-\varepsilon \mathrm{RNG}$, and $\mathrm{k}-\varepsilon$ Realizable models. All six turbulence models had a good agreement at angles of attack from $-4^{\circ}$ to $40^{\circ}$ and the same behaviour at all angles of the attack until stall. The flow was attached to the Mini-UAV throughout this regime. At an angle of attack $\left(38^{\circ}\right)$, the flow on the upper surface of the airfoil began to separate and a condition known as stall began to develop.

\section{Figure 3}

Lift Coefficient vs. Angle of Attack for Six Turbulence Models (i.e., SpalartAllmaras, $k-\varepsilon$ standard, $k-\varepsilon R N G, k-\varepsilon$ Realizable, $k-\omega$ standard, and $k-\omega S S T$ )

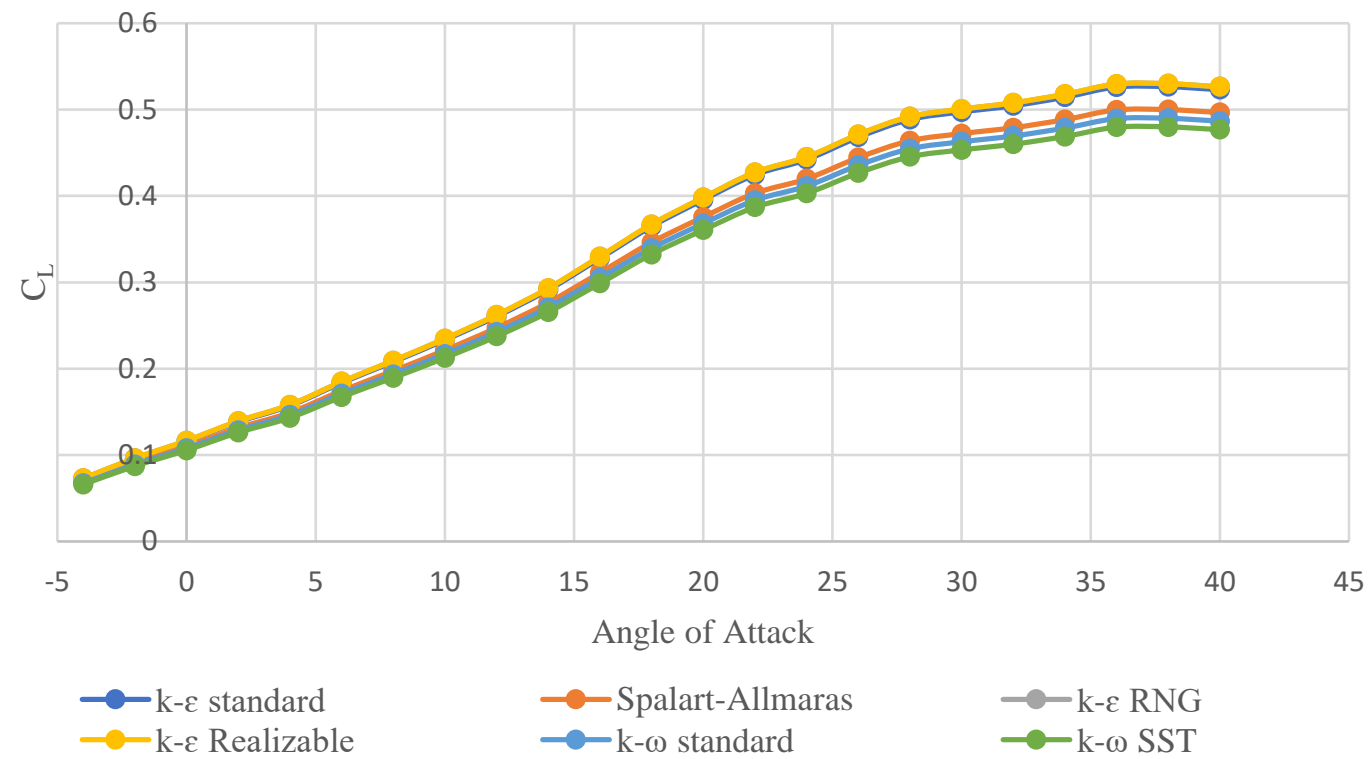


In Figure 4, the lift-to-drag ratio vs. the angle of attack for six turbulence models (i.e., Spalart-Allmaras, k- $\varepsilon$ standard, k- $\varepsilon$ RNG, k- $\varepsilon$ Realizable, k- $\omega$ standard, and k- $\omega$ SST) are shown. From the numerical results, the recorded maximum lift-to-drag ratios at $4^{\circ}$ angle of attack are 3.17, 3.24, 3.28, 3.20, 3.11, and 3.05 , respectively. The maximum variation of the lift-to-drag ratio is $7.01 \%$ at a $4^{\circ}$ angle of attack, under the influence of different turbulence model's effects. Hence, it can be said that the aerodynamic performance of Mini-UAV under different turbulence model conditions deteriorates in a negligible way.

\section{Figure 4}

Lift-to-Drag Ratio vs. Angle of Attack for Six Turbulence Models (i.e., SpalartAllmaras, $k-\varepsilon$ standard, $k-\varepsilon R N G, k-\varepsilon$ Realizable, $k-\omega$ standard, and $k-\omega S S T$ )

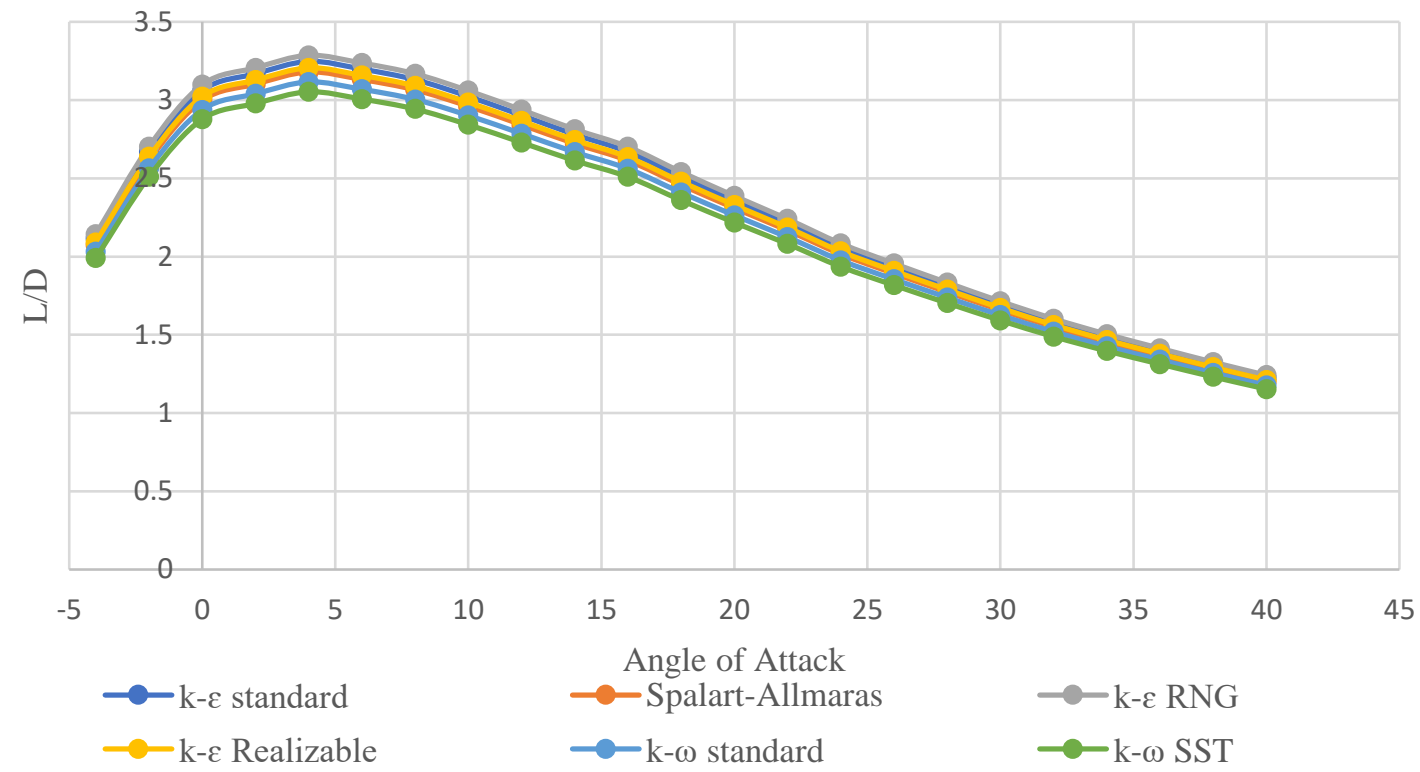

Table 1 describes the aerodynamic characteristics, numerical computation details, and modulus function for different turbulence models (i.e., SpalartAllmaras, k- $\varepsilon$ standard, k- $\varepsilon$ RNG, k- $\varepsilon$ Realizable, k- $\omega$ standard, and k- $\omega$ SST) at stall angle of attack $\left(38^{\circ}\right)$ to identify the suitable turbulent model for Mini-UAV. Since the summation of deviation of coefficients of lift and drag values i.e., 0.0166 for the Spalart-Allmaras turbulence model is less comparative to all the other turbulence models, it can be stated that the Spalart-Allmaras turbulence model is the best fit in terms of coefficients of lift and drag for Mini-UAV applications for subsonic flow. 


\section{Table 1}

Typical Variation of Required CPU Time and Aerodynamic Coefficients with Different Turbulence Models at a Stall Angle of Attack (38 )

\begin{tabular}{|c|c|c|c|c|c|c|c|c|}
\hline $\begin{array}{c}\text { Turbulent } \\
\text { Models }\end{array}$ & $\mathrm{C}_{\mathrm{L}}$ & $\mathrm{C}_{\mathrm{D}}$ & $\begin{array}{c}\text { Iteration } \\
\text { time }(\mathrm{s}) \\
\text { or CPU } \\
\text { Time }\end{array}$ & $\begin{array}{l}\text { Deviatio } \\
\mathrm{n} \text { in } \mathrm{C}_{\mathrm{D}} \\
\text { (D) }\end{array}$ & $\begin{array}{l}\text { Deviation } \\
\text { in } C_{L}(E)\end{array}$ & $\begin{array}{l}\text { Mod. } \\
\text { Of D }\end{array}$ & $\begin{array}{l}\text { Mod. } \\
\text { of E }\end{array}$ & $\begin{array}{l}\text { Summation } \\
\text { of } D \text { and } E\end{array}$ \\
\hline $\begin{array}{c}\text { Spalart- } \\
\text { Allmaras } \\
\text { (1 Eq.) } \\
\text { k-epsilon } \\
\text { (2 Eq.) }\end{array}$ & 0.5 & 0.39 & 752 & -0.0066 & -0.01 & $\begin{array}{c}0.00 \\
66\end{array}$ & 0.01 & 0.0166 \\
\hline Standard & 0.53 & 0.4 & 738 & 0.0034 & 0.02 & $\begin{array}{c}0.00 \\
34\end{array}$ & 0.02 & 0.0234 \\
\hline RNG & 0.53 & 0.4 & 780 & 0.0034 & 0.02 & $\begin{array}{c}0.00 \\
34\end{array}$ & 0.02 & 0.0234 \\
\hline Realizable & 0.53 & 0.41 & 913 & 0.0134 & 0.02 & $\begin{array}{c}0.01 \\
34\end{array}$ & 0.02 & 0.0334 \\
\hline \multicolumn{9}{|l|}{$\begin{array}{c}\text { k-omega } \\
(2 \text { Eq.) }\end{array}$} \\
\hline Standard & 0.49 & 0.39 & 889 & 0.0066 & -0.02 & $\begin{array}{c}0.00 \\
66\end{array}$ & 0.02 & 0.0266 \\
\hline SST & 0.48 & 0.39 & 959 & 0.0066 & -0.03 & $\begin{array}{c}0.00 \\
66\end{array}$ & 0.03 & 0.0366 \\
\hline
\end{tabular}

VALIDATION

Table 2 demonstrates the lift coefficients for numerical and experimental results at Mach number 0.04 for different turbulence models (i.e., SpalartAllmaras, k- $\varepsilon$ standard, k- $\varepsilon$ RNG, k- $\varepsilon$ Realizable, k- $\omega$ standard, and k- $\omega$ SST) at a stall angle of attack $\left(38^{\circ}\right)$. The numerical results are achieved, and then the experimental results are compared. Both the numerical and wind tunnel experimental results show similar trends with the stall angle of attack. The numerical results agree quite well with the corresponding wind tunnel experimental results at cruise conditions. The minimum and maximum variations of the coefficient of lift between numerical and experimental at cruise conditions are shown in Table 2. 
Table 2

The Numerical and Experimental Results at Cruise Condition

\begin{tabular}{ccc}
\hline Experimental Results & $\begin{array}{c}\text { Coefficient } \\
\text { of lift }\end{array}$ & \\
\hline $\begin{array}{c}\text { The cruise lift coefficient } \\
\text { (wind tunnel experimental results) }\end{array}$ & 0.76 & \\
Numerical Results & $\begin{array}{c}\text { Coefficient } \\
\text { of lift }\end{array}$ & $\begin{array}{c}\% \\
\text { Variation }\end{array}$ \\
Spalart-Allmaras (1 Eq.) & 0.5 & 34.21 \\
k-epsilon (2 Eq.) & & \\
Standard & 0.53 & 30.26 \\
RNG & 0.53 & 30.26 \\
Realizable & 0.53 & 30.26 \\
k-omega (2 Eq.) & & \\
Standard & 0.49 & 35.52 \\
SST & 0.48 & 36.84 \\
\hline
\end{tabular}

\section{Conclusions}

Our study focused on several aspects. Firstly, it was necessary to perform numerical simulations of the flow around the long endurance Mini-UAV using ANSYS/FLUENT software to validate the numerical simulation around this longendurance Mini-UAV. Secondly, this aerodynamic flow was modelled by six different models (i.e., Spalart-Allmaras, k- $\varepsilon$ standard, k- $\varepsilon$ RNG, k- $\varepsilon$ Realizable, k$\omega$ standard, and $k-\omega$ SST) to compare and validate the most efficient model in this simulation. The main conclusion that can be drawn from this stage of the study for the aerodynamic characteristics' results is that the six turbulence models have the same general behaviour with some differences in the coefficients of lift and drag. We conclude that the Spalart-Allmaras, k- $\varepsilon$ standard, k- $\varepsilon$ RNG, k- $\varepsilon$ Realizable models give closer results to the experimental results. Since the summation of deviation of coefficients of lift and drag values for the SpalartAllmaras turbulence model is 0.0166 , it is the best fit in terms of coefficients of lift and drag for Mini-UAV applications. Our study thus tends to show that the Spalart-Allmaras model is the most efficient model to model the turbulence of the subsonic flow around a Mini-UAV application based on the summation of deviation of coefficients of lift and drag values, Iteration time (s), or CPU Time. 
V and A: Comparative Study on the Prediction of Aerodynamic Characteristics of M ini - UAV with Turbulence M odels

\section{References}

Bronz, M., Hattenberger, G., \& Moschetta, J.-M. (2013). Development of a long endurance mini-UAV: ETERNITY. International Micro Air Vehicle Conference and Flight Competition (IMAV2013) 17-20 September 2013, Toulouse, France.

Civil Aviation Authority. (2015). CAA's SUAS definition. https://www.caa.co.uk/ Coombs, J. L., Doolan, C. J., Moreau, D. J., Zander, A. C., \& Brooks, L. A. (2012). Assessment of turbulence models for a wing-in-junction flow. 18th Australasian Fluid Mechanics Conference Launceston, Australia 3-7 December 2012.

Eleni, D. C., Athanasios, T. I., \& Dionissios, M. P. (2012). Evaluation of the turbulence models for the simulation of the flow over a National Advisory Committee for Aeronautics (NACA) 0012 airfoil. Journal of Mechanical Engineering Research, 4(3), 100-111 doi:10.5897/JMER11.074 ISSN 2141-2383

Federal Aviation Administration. (2015). FAA SUAS regulation (2015). https://www.faa.gov/news/press_releases/news_story.cfm?newsId=19856

Hanjalic, K., \& Launder, B. E. (1972). A Reynolds stress model of turbulence and its application to thin shear flows. Journal of Fluid Mechanics, 52(4), 609-638.

Jang, Y., Huh, J., Lee, N., Lee, S., Park, Y. (2018). Comparative study on the prediction of aerodynamic characteristics of aircraft with turbulence models. International Journal of Aeronautical \& Space Sciences, 19, 1323. https://doi.org/10.1007/s42405-018-0022-6

Jones, W. P., \& Launder, B. E. (1972). The prediction of laminarization with a two-equation model of turbulence. International Journal of Heat Mass Transfer, 15, 301-314.

Kwak, E., Lee, N., \& Lee, S. (2012). Performance evaluation of two-equation turbulence models for 3D wing-body configuration. International Journal of Aeronautical \& Space Science, 13(3), 307-316. doi:10.5139/JJASS.2012.13.3.307

Launder, B. E., \& Spalding, D. B. (1974). The numerical computation of turbulent flows. Computer Methods in Applied Mechanics and Engineering, 3, 269289.

Launder, B. E., \& Spaslding, D. B. (1972). Lectures in mathematical models of turbulence. Academic Press.

Lin, Z. (2008). UAV for mapping - Low altitude photogrammetric survey. The International Archived of the Photogrammetry, Remote Sensing and Spatial Information Sciences, XXXVII(B1). http://citeseerx.ist.psu.edu/ viewdoc/download?doi=10.1.1.150.9698\&rep=rep1\&type=pdf 
Maani, R. E., Elouardi, S., Radi, B., \& ELHami, A. (2018). Study of the turbulence models over an aircraft wing. doi:10.21494/ISTE.OP.2018.0306

Menter F. R. (1994). Two-equation eddy-viscosity turbulence models for engineering applications. AIAA Journal, 32(8), 1598-1605.

Menter, F. R. (1994). Two-equation eddy viscosity models for engineering applications. AIAA Journal, 32(8),1598-1605.

Ng, K. H., \& Spalding, D. B. (1972). Turbulence model for boundary layers near walls. The Physics of Fluids, 15(1), 20-30.

Park, D., Lee, Y., Cho, T., \& and Kim, C. (2018) Design and performance evaluation of propeller for solar-powered high-altitude long-endurance unmanned aerial vehicle. International Journal of Aerospace Engineering, 2018, Article ID 5782017. https://doi.org/10.1155/2018/5782017

Prandtl, L. (1949). Report on investigation of developed turbulence. Technical Report 1231. National Advisory Committee for Aeronautics.

Savla, K., Nehme, C., Temple, T., \& Frazzoli, E. (2008). On efficient cooperative strategies between humans and UAVs in a dynamic environment. AIAA Conference on Guidance, Navigation and Control, Honolulu, HI, USA, 2008.

SESARJU. (2021). SESAR-reviewed SUAS definition. https://www.sesarju.eu/

Shih, T. H, Liou, W. W., Shabbir, A., \& Zhu, J., (1995). A new k- $\varepsilon$ eddy viscosity model for high Reynolds number turbulent flows - model development and validation. Computers Fluids, 24, 227-238.

Son, S.-H., Choi, B.-L., Jin, W.-J., Lee, Y.-G., Kim, C.-W., \& Choi, D.-H. (2016). Wing design optimization for a long-endurance UAV using FSI analysis and the Kriging method. International Journal of Aeronautical \& Space Science, 17(3), 423-431. doi:10.5139/IJASS.2016.17.3.423

Spalart, P. R., \& Allmaras, S. R. (1992). A one-equation turbulence model for aerodynamic flows. AIAA 30th Aerospace Sciences Meeting. Reno, NV, January, 1992.

Spalart, P. R., \& Allmaras, S. R. (1993). A one-equation turbulence model for aerodynamic flows. AIAA Paper 1993-0439. https://doi.org/10.2514/6.1992-439

Voloshin, V., Chena, Y. K., \& Calay, R. (2012). A comparison of turbulence models in airship steady-state CFD simulations. arXiv:1210.2970v1 [physics.flu-dyn] 10 Oct 2012.

Wang, Y.-C., Sheu, D.-S., Tsai, C., Huang, H.-J., \& Lai, Y.-H. (2013). Performance analysis and flight testing for low altitude long endurance unmanned aerial vehicles. Journal of Aeronautics, Astronautics, and Aviation, Series A, 45(1), 37 - 044. doi:10.6125/12-1218-721 
V and A: Comparative Study on the Prediction of Aerodynamic Characteristics of M ini - UAV with Turbulence M odels

Wilcox, D. C. (1988). Reassessment of the scale-determining equation for advanced turbulence models. AIAA Journal, 26(11), 1299-1310.

Wilcox, D. C. (1994). Turbulence modelling for CFD. https://cfd.spbstu.ru/ agarbaruk/doc/2006_Wilcox_Turbulence-modeling-for-CFD.pdf 